\title{
Bacterial Colonization of Intensive Care Unit Environment and Healthcare Workers in A Tertiary Care Hospital in Kolar Region, India
}

\author{
R. Kalyani ${ }^{1}$, N. Arvind ${ }^{2 *}(\mathbb{D})$, N. Suresh Kumar ${ }^{3}\left(\mathbb{D}\right.$, Mahendra M Reddy $^{4}$ and \\ K. Dinesh ${ }^{3}$ \\ ${ }^{1}$ Sri Devaraj Urs Medical College, SDUAHER, Tamaka, Kolar - 563 101, Karnataka, India. \\ ${ }^{2}$ Department of Microbiology, Sri Devaraj Urs Medical College, SDUAHER, Tamaka, \\ Kolar - 563 101, Karnataka, India. \\ ${ }^{3}$ Department of Anesthesiology, Sri Devaraj Urs Medical College, SDUAHER, Tamaka, \\ Kolar - 563 101, Karnataka, India. \\ ${ }^{4}$ Department of Community Medicine, Sri Devaraj Urs Medical College, SDUAHER, Tamaka, \\ Kolar - 563 101, Karnataka, India.
}

\begin{abstract}
Direct shedding of microbes by patients and health care workers results in contamination of Intensive care unit environment. Intensive care unit acquired infections due to microbial contamination is a major concern because the patient's immunity is already compromised. To determine the rate of bacterial contamination on environmental surfaces of Intensive care unit and health care workers and to determine the antibiogram of the isolates. Air samples and swabs from healthcare workers, their accessories, surrounding environmental surfaces were collected randomly over a period of 2 months in Adult Intensive care units. Bacterial isolates were identified by standard microbiological techniques. Antibiotic sensitivity testing was performed by Kirby Bauer disc diffusion method and data analyzed by Statistical Product and Service Solutions 22 version software. A total of 208 samples were randomly collected over 2 months, of which 56 samples yielded positive bacterial growth. Of 56 growth, 12 isolates were detected from air sampling method and $\mathbf{4 4}$ isolates from swabs. Among $\mathbf{4 4}$ isolates identified from swabs, 10 were isolated from healthcare workers, 4 from health ca re worker's accessories and 30 from environmental surfaces. Six different bacterial isolates were identified, Coagulase Negative Staphylococcus (24) and Micrococcus (15) were the major isolates followed by Non fermenters (6), Staphylococcus aureus(4), Bacillus species(4) and diphtheroids (3) The antimicrobial sensitivity pattern of these bacterial isolates were sensitive to commonly used antibacterial agents. Study results showed Intensive care unit staff and environmental surfaces as probable sources of bacterial contamination. Study highlights the importance of cleaning and disinfection process and educate the health care workers about the possible sources of infections within Intensive care unit.

Keywords: Bacterial contamination, Intensive care unit, antibiotic sensitivity
\end{abstract}

*Correspondence: drlotus147@yahoo.co.in; +91 7406614777

(Received: April 27, 2020; accepted: January 27, 2021)

Citation: Kalyani R, Arvind N, Kumar NS, Reddy MM, Dinesh K. Bacterial Colonization of Intensive Care Unit Environment and Healthcare Workers in A Tertiary Care Hospital in Kolar Region, India. J Pure Appl Microbiol. 2021;15(1):402-409. doi:10.22207/ JPAM.15.1.37

(c) The Author(s) 2021. Open Access. This article is distributed under the terms of the Creative Commons Attribution 4.0 International License which permits unrestricted use, sharing, distribution, and reproduction in any medium, provided you give appropriate credit to the original author(s) and the source, provide a link to the Creative Commons license, and indicate if changes were made. 


\section{INTRODUCTION}

Intensive care unit (ICU) is an essential element of effective health care services that caters the care of resuscitation, management and monitoring of critically ill patients ${ }^{1}$. The microbial contamination of intensive care units is of a major concern as it can contribute to ICU acquired infections. Breach in the body barriers due to invasive devices, surgery, co-morbid conditions like diabetes, hypertension etc and prolonged antimicrobial exposure compromise patient's immunity admitted in $\mathrm{ICU}^{2}$.

In health care facilities, ICU acquired infections accounts for more than $20 \%$ of nosocomial infections ${ }^{3}$. The clinical activities in ICU involves use of higher antibiotics, minor procedures, invasive monitoring, and managing critically ill patients, all these factors favour the emergence of multidrug resistant bacterial strains resulting in high morbidity and mortalityrate ${ }^{4}$.

The contaminated environmental surfaces play a significant role in the transmission of healthcare associated pathogens ${ }^{5}$. In ICU patients are surrounded by equipment for monitoring the vitals and organ support like ventilator, infusion pumps and resuscitation trolleys ${ }^{6}$. The contamination of ICU environment and medical devices may occur as the consequence of cross transmission or direct shedding of microbes by patient or by healthcare workers $(\mathrm{HCWs})^{7}$. In addition, the ICU staff can serve as vehicles for the spread of resident pathogens among patients in ICU's ${ }^{8}$.

Periodic surveillance of ICU is essential to ascertain the level of bacterial contamination on environmental surfaces and HCW's. The study was conducted to determine the rate of bacterial contamination on environmental surfaces in Intensive care unit and health care workers and to determine the antibiogram of the isolates.

\section{MATERIALS AND METHODS \\ Study Setting, design and period}

Across-sectional descriptive study was conducted from July-August 2019 at Adult Intensive Care Unit of R L Jalappa Hospital and Research Centre,a tertiary care teaching hospital in rural Kolar region, Karnataka, India Air Samples and swabs from HCW's, their accessories and environmental surfaces was collected randomly once in 2 weeks over 2 months period in Adult intensive care unit of 30 bedded capacity. A total of 4 rounds of surveillance was conducted over the study period two months duration accounting for a total of 208 samples ( 52 samples in each round).

In each round of surveillance, 20 samples from environmental surfaces, 12 samples from anterior nares and hands of HCWs (two Intensivists, two Nurses and two housekeeping staff) 15 from HCWs accessories (mobile, pen, stethoscopes and rings) and 5 from air samples i.e a total of 52 samples were collected.

Swabs from the both right and left anterior nares and hands of ICU HCWs (2 Intensivists, 2 Nurses and 2 housekeeping staff) and their accessories (mobile, pen, stethoscopes and rings) were collected. Swab samples were chosen randomly and collected from ICU environmental surfaces and devices that were in close contact with the patients. Twenty swabs were collected from floor, walls, door handles, taps, bed linens, iv sets, beds, cot, nursing station, trolleys, ambu bags, oxygen masks, ventilators, suction machine, sphygmomanometer, table, chairs, patient files, telephone handsets and stethoscopes.

\section{Collection and Processing}

\section{Air sample}

Air sampling was done by settle plate method. Open Blood Agar and MacConkey agar plates, prelabeled with site area were placed at 5 areas (4 corners and 1 at the centre) of the ICU about 1 meter above the ground, 1 meter from the wall and exposed for 1 hour following the schedule $1 / 1 / 1^{9}$. Plates were transported to the Microbiology laboratory within 10 minutes at room temperature. These plates were incubated at $37^{\circ} \mathrm{C}$ for 24 to 48 hours in microbiology laboratory, was observed for any bacterial growth.

\section{Swab sample}

Prelabeled sterile swab were moistened in sterilesaline and was rolled over the inanimate surfaces, equipment's, HCWs hands, anterior nares and the nit was transported to the microbiology laboratory within 10 minutes at room temperature. The swabs were immediately streakedon to Blood agar and MacConkey agar media and incubated at $37^{\circ} \mathrm{C}$ for $24-48$ hours in microbiology laboratory, was observed for any bacterial growth.

Any bacterial growth was further identified using standard bacteriological methods 
and appropriate biochemical tests carried out based on the standard operating procedure (like gram stain, catalase, coagulase, oxidase, indole, citrate, urease, mannitol motility and triple sugar iron tests) $)^{10,11}$.

\section{Antibiotic susceptibility testing}

Susceptibility testing was done on Mueller Hintonagar for all isolates by Kirby Bauer disc diffusion method according to the latest CLSI guidelines. Cefoxitin disc was used for the screening of Methicillin Resistant Staphylococcus aureus (MRSA) ${ }^{12}$.

\section{Quality contro}

Escherichiae coli ATCC 25922, Klebsiella pneumoniae ATCC 700603, Pseudomonas aeruginosa ATCC 27853, Staphylococcus aureus ATCC 25923 and Enterococcus faecalis ATCC29212 were used for Internal qualitycheck.

\section{Statistical Methods}

Data was entered into Microsoft excel data sheet and was analysed using Statistical Product and Service Solutions (SPSS)22Version software.

\section{Ethical Approval}

The study protocol was approved by the Institutional Ethical committee of Sri Devaraj Urs Medical College. (Reference no SDUMC/KLR/ IEC/287/2019-20). The HCWs were included in the study after obtaining informed participant consent

\section{RESULTS}

A total of 208 samples were collected from 4 rounds of surveillance, of which $56(26.92$ $\%)$ samples yielded positive bacterial growth. Of these 56-positive growth, 12 (21.36\%) were

Table 1. Distribution of bacteria on the various sites in ICU

\begin{tabular}{|c|c|c|c|c|c|c|c|}
\hline Site & S.aureus & CONS & Micrococcus & Bacillus & Diphtheroids & NFGNB & TOTAL \\
\hline Settle plate & & 5 & 6 & 1 & & & $12(21.36)$ \\
\hline HCW Nasal swab & 3 & 6 & & & 1 & & $10(17.8)$ \\
\hline HCW mobile & & & 2 & & & & $2(3.56)$ \\
\hline $\mathrm{HCW}$ rings & & 2 & & & & & $2(3.56)$ \\
\hline Door handle & & 1 & & & & & $1(1.78)$ \\
\hline ICU tap & & & & 1 & & 2 & $3(5.34)$ \\
\hline Bed linen & & & 1 & & 1 & & $2(3.56)$ \\
\hline IV set stand & & 1 & & & & & $1(1.78)$ \\
\hline Cot & & 1 & & & & 1 & $2(3.56)$ \\
\hline Nursing station & & 1 & & & & & $1(1.78)$ \\
\hline Trolley medication & & & 1 & & & & $1(1.78)$ \\
\hline Ambu bags & & 1 & 1 & & & & $2(3.56)$ \\
\hline Oxygen mask & & 1 & & & & & $1(1.78)$ \\
\hline Suction apparatus & & 1 & & & & & $1(1.78)$ \\
\hline Telephone set & & & 1 & & & & $1(1.78)$ \\
\hline Patient Files & & & & & 1 & & $1(1.78)$ \\
\hline Stethoscope & & & 1 & & & & $1(1.78)$ \\
\hline Multipara monitor & & & & 1 & & & $1(1.78)$ \\
\hline Handwash sink & 1 & & & & & 1 & $2(3.56)$ \\
\hline Ultrasound & & & 1 & & & & $1(1.78)$ \\
\hline ABG Analyzer & & 1 & & & & & $1(1.78)$ \\
\hline ECG Leads & & & & & & 2 & $2(3.56)$ \\
\hline Computer mouse & & 1 & & & & & $1(1.78)$ \\
\hline Computer keyboard & & & 1 & & & & $1(1.78)$ \\
\hline Dressing trolley & & 1 & & & & & $1(1.78)$ \\
\hline Refrigerator & & & & 1 & & & $1(1.78)$ \\
\hline Camera monitor & & 1 & & & & & $1(1.78)$ \\
\hline Total & $4(7.14)$ & $24(42.72)$ & $15(26.7)$ & $4(7.14)$ & $3(5.34)$ & $6(10.71)$ & $56(100)$ \\
\hline
\end{tabular}

HCWs - Health care workers; CONS - Coagulase negative Staphylococcus; S. aureus - Staphylococcus aureus NFGNB - Non fermenting Gram negative bacilli; Numerical value in the bracket denotes percentage 
isolated from Air sampling method and 44 (78.57 \%) by swab samples.

Among 44 (78.57 \%) positives growth from swabs, 10 (17.8\%), 4 (7.14\%) and30 (53.4\%) were isolated from HCW's, their accessories and environmental surfaces respectively as shown in Table 1.

Six different bacterial isolates were identified. Coagulase Negative Staphylococcus (CONS) 24 (42.72\%) and Micrococcus 15 (26.7\%) accounted for majority of the isolates followed by Non fermenters 6 (10.71\%)Staphylococcus aureus 4 (7.14\%), Bacillus 4 (7.14\%) and diphtheroids 3 (5.34\%).

Bacterial contamination of ICU from environmental surfaces, inanimate objects, health care workers and air quality are represented in Table 1.

CONS 24 (42.72\%) and Micrococcus $15(26.7 \%)$ accounted for high contamination rate. More than 1 isolate was observed from ICU taps, handwash sink, ECG leads, ambu bags, cot, bed linen as evidenced in the Table 1.

No microbial contamination was detected on the following objects -IV infusion sets, bed railings, ventilators, sphygmomanometer, dialysis machine, defibrillator, walls and partition curtains.

The antibiogram of Gram positive and Gram negative bacterial isolates are shown in the Table 2 and 3 respectively. The isolates were sensitive to most of the commonly used
Antibacterial agents. No Multidrug resistant bacteria isolated in our study.

\section{DISCUSSION}

ICU acquired infections accounts for major health problem globally leading to higher morbidity and mortality. The potential sources of ICU infections are patient's flora (40-60\%) followed by health care workers and their accessories (20$40 \%$ ) and contaminated environmental surfaces and equipment $(20 \%)^{13}$.

The prevalence of ICU acquired infections in developed countries is around 5-10\%, while their prevalence exceeds 2-20 times higher in developing countries ${ }^{14}$.

The results of our study showed higher contamination of the environmental surfaces and medical devices by Gram positive 24 (80\%) when compared to Gram negative 6 (20\%) types. Gram positive bacteria were predominantly comprised of Coagulase negative Staphylococcus followed by Micrococcus, Bacillus, Diphtheroids and Staphylococcus aureus. Non fermenters were isolated among Gram negative bacteria. Our findings were concurrent with a study conducted by Tajeddin et al. which showed contamination is more with Gram positive than Gram negative $(60.7 \% \mathrm{v} / \mathrm{s} 39.3 \%)^{15}$. This may be due to the better survival of Gram positive bacteria in contrast to the Gram negative bacteria in dryair ${ }^{16,17}$.

Table 2. Antibiotic sensitivity pattern of Gram positive bacteria isolated from ICU

\begin{tabular}{lccccc}
\hline Antibiotics & $\begin{array}{c}\text { S.aureus } \\
\mathrm{N}=4\end{array}$ & $\begin{array}{c}\text { CONS } \\
\mathrm{N}=24\end{array}$ & $\begin{array}{c}\text { Micrococcus } \\
\mathrm{N}=15\end{array}$ & $\begin{array}{c}\text { Bacillus } \\
\mathrm{N}=4\end{array}$ & $\begin{array}{c}\text { Diphtheroids } \\
\mathrm{N}=3\end{array}$ \\
\hline Penicillin & $0(0)$ & $18(82.8)$ & $12(79.9)$ & $4(100)$ & $3(100)$ \\
Erythromycin & $2(50)$ & $22(99.52)$ & $12(79.9)$ & $3(75)$ & $3(100)$ \\
Ciprofloxacin & $2(50)$ & $20(83.2)$ & $13(86.5)$ & $4(100)$ & $2(66.6)$ \\
Cefazolin & $3(75)$ & $22(99.52)$ & $15(100)$ & $4(100)$ & $3(100)$ \\
Gentamicin & $3(75)$ & $22(99.52)$ & $14(93.2)$ & $3(75)$ & $3(100)$ \\
Cotrimoxazole & $3(75)$ & $20(83.2)$ & $13(86.5)$ & $3(75)$ & $2(66.6)$ \\
Tetracycline & $3(75)$ & $23(95.68)$ & $15(100)$ & $4(100)$ & $3(100)$ \\
Chloramphenicol & $4(100)$ & $24(100)$ & $15(100)$ & $4(100)$ & $3(100)$ \\
Amoxycillin clavulanic & $4(100)$ & $24(100)$ & $15(100)$ & $4(100)$ & $3(100)$ \\
acid & & & & & $3(100)$ \\
Linezolid & $4(100)$ & $24(100)$ & $15(100)$ & $4(100)$ & $3(100)$ \\
Vancomycin & $4(100)$ & $24(100)$ & $15(100)$ & $4(100$ & 3 \\
\hline
\end{tabular}

Numerical in the Bracket denotes percentage \% 
Table 3. Antibiotic sensitivity pattern of Gram negative bacteria isolated from ICU

\begin{tabular}{lc}
\hline Antibiotics & NFGNB (N =6) \\
\hline Cotrimoxazole & $1(16.66)$ \\
Ciprofloxacin & $1(16.66)$ \\
Ceftazidime & $1(16.66)$ \\
Levofloxacin & $1(16.66)$ \\
Doxycycline & $2(33.33)$ \\
Amikacin & $3(50)$ \\
Cefepime & $3(50)$ \\
Tobramycin & $4(66.66)$ \\
Piperacillin & $4(66.66)$ \\
Piperacillin & $6(100)$ \\
Tazobactum & \\
Imipenem & $6(100)$ \\
Meropenem & $6(100)$ \\
\hline
\end{tabular}

In contrast to our findings, a study done by Jadhav et al. reported that Gram negative bacteria contributed a major proportion on the ICU inanimate objects than Gram positive $(68.8$ $\% \mathrm{v} / \mathrm{s} 31.1 \%)^{18}$. This may be due to the intrinsic resistance exhibited by Gram negative bacteria to disinfectants as their cell wall is impermeable to active biocide agents and they also possess degradative enzymes ${ }^{19}$.

Indoor air contamination of ICU accounts for $10-33 \%$ of Nosocomial infections ${ }^{20}$. Our study showed indoor air quality surveillance assessed by Air sampling method yielded Coagulase Negative Staphylococcus 6 (50\%) followed by Micrococcus 5 (41.6\%), and Bacillus 1(8.3\%). These isolates could be commensal flora of human skin, mucus membranes that are continuously shred ${ }^{21,22}$.

A study conducted by Kiranmai et al. showed ICU air sample was highly contaminated with bacteria like Bacillus Spp as well as potential pathogens like Klebsiella, Pseudomonas ${ }^{23}$. No potential pathogens were isolated from our study. Our study showed lesser air contamination of 12 (21.3\%) with Micrococcus and CONS as predominant isolates which could be commensal flora. This could be attributed to lesser movement of staff members and restriction of visitors and better infection control practices. The high level of air contamination in other studies may be attributed to the movement of large equipment, increased movement of staff numbers, bed changes, patient personal hygiene, increase visiting hours and inadequate cleaning ${ }^{24}$.

Several studies document that hands of ICU staff accounts for $20-40 \%$ infections due to the cross transmission between colonised / infected patients ${ }^{25,26}$. A study conducted by Tajeddin et al. on the hands of ICU staff yielded Acinetobacter baumannii (1.4\%), Staphylococcus aureus (5.9\%), epidermidis (20.9\%) and Enterococcus spp. $(1 \%)^{15}$. In contrast, our study did not show any evidence of bacterial colonization from the HCWs hand swabs collected before performing procedures. This can be attributed to compliance of our HCWs to hand hygiene practices.

There are several studies confirming the nasal colonization of MRSA as a major risk factor for infections in ICU caused by the colonizing strain ${ }^{27-29}$. The study conducted by Joanchim et al. showed the prevalence of MRSA carriers among HCWs was 59/379 (15.6\%) ${ }^{30}$. A study conducted by Warnke et al. revealed that bacterial detection depends on the uptake and release capacities of the swabs and the swabbing techniques ${ }^{31}$. In our study, screening of the Nasal swabs of the health care workers (Intensivists / Nursing staff/ housekeeping staff) didn't show any evidence of MRSA colonization, but showed the presence of Staphylococcus aureus (8.92\%), Coagulase Negative Staphylococcus (10.71\%) and diphtheroids (1.78\%)

The accessories (Stethoscopes, mobiles, pens) used by the HCWs for the improvement of the patients may pose a major threat to patients admitted in $\mathrm{ICU}^{32,33}$. A study conducted by Lavanya et al. showed that $56 \%$ of mobile phones, $52 \%$ of the stethoscopes, $40 \%$ of finger rings, and $28 \%$ of the pens used by ICU staff showed growth of coagulase negative Staphylococcus spp. (70.46\%), Staphylococcus aureus (13.69\%) and Acinetobacter spp $(11.64 \%)^{34}$. In our study it was observed that the accessories of $\mathrm{HCW}$ yielded CONS(3.56\%) and Micrococcus (3.56\%). This could be attributed to strict infection control practices by our ICU staff.

The ICU sinks are used for cleaning hands and medical equipment before disinfection and to flush patient's secretions / fluids. These activities can induce biofilm production and emergence of multidrug resistance and acts as a potential source ${ }^{35}$. 
A study conducted by Geyter et al. revealed that the sink in the ICU was a potential source of infection resulting in many outbreaks of Carbapenemase producing Enterobacteriaceae ${ }^{36}$. Another study conducted by Kramer et al. found that $100 \%$ of the sinks in an ICU were contaminated with Gram negative bacilli due to several non-hand hygiene activities ${ }^{37}$. In our study, ICU sink and the tap showed lesser contamination and yielded Non fermenters and Staphylococcus aureus which accounted for only8.92\%.

The antibiotic sensitivity pattern of our isolates showed low rates of drug resistance in contrast with other studies where they have reported high resistant pattern ${ }^{38,39}$. None of our isolates were resistant to reserve antibiotics like vancomycin, linezolid, piperacillin tazobactum and carbapenems. Our study did not yield any MDR isolates, may be due to the strict adherence of our Intensivists to antibiotic policies/antimicrobial stewardship program. The high resistance pattern reported by other studies may be attributed to the selective pressure due to extensive use of broadspectrum antibiotics ${ }^{40}$.

\section{CONCLUSION}

Our study results showed ICU staff as well as environmental surfaces as probable sources of bacterial contamination. Bacterial contamination can contribute to ICU acquired infections. HCWs should be aware of the risk of cross-transmission of microbes between them to inanimate surfaces and vice versa. The hospital infection control and prevention team should conduct periodic surveillance, effective cleaning of environmental surfaces, sterilizing the instruments before and after use, and strictly adhere to basic standard precautions at all the times during health care activities.

\section{ACKNOWLEDGMENTS}

We investigators acknowledge the support rendered by STS program of ICMR for approving our project (2019-8387) and granting stipend to the student.

\section{CONFLICT OF INTEREST}

The authors declare that there is no conflict of interest.

\section{AUTHORS' CONTRIBUTION}

KR helped in Collection and processing of samples, collection of data. AN helped in designed of the study, processing of the samples, analysis and interpretation of sample, analysing data and writing the paper. SKN and DK helped in Revision of intellectual contents, interpretations of samples, manuscript editing. MMR helped in statistical analysis and editing of manuscript.

\section{FUNDING}

This work was supported by the STS program of ICMR (Reference number 2019-8387)

\section{DATA AVAILABILITY}

All datasets generated or analyzed during this study are included in the manuscript.

\section{ETHICS STATEMENT}

The institutional ethics committee of Sri Devaraj URS medical college, tamaka, kolar has examined and unanimously approved this study.

\section{REFERENCES}

1. Yusuf JB, Okwong OK, Mohammed A, et al. Bacterial Contamination of Intensive Care Units at a Tertiary Hospital in Bauchi, North eastern Nigeria. Amer $J$ of Int Med. 2017;5(3): 46-51. doi: 10.11648/j. ajim.20170503.13

2. Russotto V, Cortegiani A, Fasciana T, et al. What Healthcare Workers Should Know about Environmental Bacterial Contamination in the Intensive Care Unit. Hindawi BioMed Res Int. 2017;2017:6905450. doi: 10.1155/2017/6905450.

3. Ulu-Kilic A, Ahmed SS, Alp E, Doganay M. Challenge of intensive care unit -acquired infections and Acinetobacter baumannii in developing countries. OA Crit Care. 2013;1(1):1-5.

4. CatanoJC, Echeverri LM, Szela C. Bacterial contamination of clothes and environmental items in a third-level hospital in Colombia. Interdiscip Perspect Infect Dis. 2012;2012:507640. doi:10.1155/2012/507640

5. Suleyman G, Alangaden G, Bardossy AC. The Role of Environmental Contamination in the Transmission of Nosocomial Pathogens and Healthcare- Associated Infections. Curr Infect Dis Rep. 2018;20(6):12. doi: 10.1007/s11908-018-0620-2

6. Russotto V, Cortegiani A, Raineri SM, Giarratano A. Bacterial contamination of inanimate surfaces and equipment in the intensive care unit. J Intensive Care. 2015;3:54. doi:10.1186/s40560-015-0120-5

7. Siobhan S, Chipchase LS. Healthcare equipment as a source of nosocomial infection: A systematic review. $J$ of Hosp Infect. 2006:63(3):239-245. doi: 10.1016/j. jhin.2005.10.013

8. Nseir S, Blazejewski C, Lubret R, Wallet F, Courcol 
R, Durocher A. Risk of acquiring multidrug-resistant Gram-negative bacilli from prior room occupants in the intensive care unit. Clin Microbiol Infect. 2011;17(8):1201-1208. doi: 10.1111/j.14690691.2010.03420.x

9. Pasquarella C, Pitzurra O, Savino A. The index of microbial air contamination. J Hosp Infect. 2000;46(4):241-256. doi: 10.1053/jhin.2000.0820

10. Retty AF, Daniel FS and Aice SW. Bailey and Scotts of Diagnostic Microbiology. 14th ed. Press, Houston, Texas. 2017.

11. Nasser NE, Abbas AT, Hamed SL. Bacterial contamination in intensive care unit at Al-Imam Al-Hussein Hospital in Thi-qar province in Iraq. Glob J Health Sci. 2013;5(1):143-149. doi:10.5539/gjhs. v5n1p143

12. CLSI. Performance standards for Antimicrobial Susceptibility testing. 29th ed.CLSI supplement M100. Wayne P A: Clinical and Laboratory Standards Institute. 2019.

13. Weinstein RA. Epidemiology and control of nosocomial infections in adult intensive care units. Am J Med. 1991;91(3 Suppl. 2)):179S-184S. doi: 10.1016/00029343(91)90366-6

14. Darge A, Kahsay AG, Hailekiros H, Niguse S, Abdulkader $M$. Bacterial contamination and antimicrobial susceptibility patterns of intensive care unit's medical equipment and inanimate surfaces at Ayder Comprehensive Specialized Hospital, Mekelle, Northern Ethiopia. BMC Res Notes. 2019;12:621. doi: 10.1186/s13104-019-4658-5

15. Tajeddin E, Rashidan M, Razaghi M, et al. The role of the intensive care unit environment and health-care workers in the transmission of bacteria associated with hospital acquired infections. I Infect Public Health. 2016;9(1):13-23. doi: 10.1016/j.jiph.2015.05.010

16. Dickgiesser N. Behaviour of gram-positive and gram-negative bacteria in dry and moist atmosphere (author's transl)]. Zentralbl Bakteriol B. 1978;167(12):48-62. PMID: 716702.

17. Kramer A, Schwebke I, Kampf G. How long do nosocomial pathogens persist on inanimate surfaces? A systematic review. BMC Infect Dis. 2006;6:130. doi:10.1186/1471-2334-6-130.

18. Jadhav S, Sahasrabudhe T, Kalley V, Gandham N. The microbial colonization profile of respiratory devices and the significance of the role of disinfection: a blinded study. J Clin Diagn Res. 2013;7(6):1021-1026. doi: $10.7860 / J C D R / 2013 / 5681.3086$

19. Russell AD. Bacterial resistance to disinfectants: present knowledge and future problems. J Hosp Infect. 1999;43(Suppl 1):S57-S68. doi: 10.1016/s01956701(99)90066-x

20. Chang CY, Tseng L, Yang LS. Microbial air contamination in an intensive care unit. Int J. Public Health Sci. 2015;4(3):145-151. doi: 10.11591/ijphs.v4i3.4725

21. Sivagnanasundaram $P$, Amarasekara RWK, Madegedara RMD, Ekanayake A, Magana-Arachchi DN. Assessment of Airborne Bacterial and Fungal Communities in Selected Areas of Teaching Hospital, Kandy, Sri Lanka. Biomed Res Int. 2019;2019:7393926. doi: 10.1155/2019/7393926
22. Laxmi R, Khatri P K, Saroj M, Archana B, Niranjan S and Shivani k. Investigation of bacterial counts in air at different wards of a tertiary care hospital, Western Rajasthan. Int J of Sci Res. 2015;(3):3396-3400.

23. Kiranmai S, Madhavi K.S. Microbiological surveillance of operation theatres, intensive care units and labor room of a teaching hospital in Telangana, India. Int J of Res Med Sci. 2016;4(12):5256-5260. doi: 10.18203/2320-6012.ijrms20164190

24. Thompson DR, Hamilton DK, Cadenhead CD, Swoboda SM, Schwindel SM, Anderson DC et al. Guidelines for intensive care unit design. Crit Care Med. 2012;40(5):1586-1600. doi: 10.1097/ CCM.0b013e3182413bb2

25. Tschudin-Sutter S, Pargger H, Widmer AF. Hand hygiene in the intensive care unit. Crit Care Med. 2010;38(8 Suppl):S299-S305. doi: 10.1097/ CCM.0b013e3181e6a23f

26. Birnbach DJ, Rosen LF, Fitzpatrick M, Arheart KL, Munoz-Price LS. An evaluation of hand hygiene in an intensive care unit: Are visitors a potential vector for pathogens? J Infect Public Health. 2015;8(6):570-574. doi: 10.1016/j.jiph.2015.04.027

27. Qiao F, Huang W, Cai L, Zong Z, Yin W Methicillinresistant Staphylococcus aureus nasal colonization and infection in an intensive care unit of a university hospital in China. J Int Med Res. 2018;46(9):3698-3708. doi: 10.1177/0300060518777812

28. Lucet J, Chevret S, Durand-Zaleski I, Chastang C, Regnier B, for the Multicenter Study Group. Prevalence and Risk Factors for Carriage of Methicillin-Resistant Staphylococcus aureus at Admission to the Intensive Care Unit: Results of a Multicenter Study. Arch Intern Med. 2003;163(2):181-188. doi: 10.1001/ archinte.163.2.181

29. Sakr A, Bregeon F, Mege JL, Rolain JM, Blin O. Staphylococcus aureus Nasal Colonization: An Update on Mechanisms, Epidemiology, Risk Factors, and Subsequent Infections. Front Microbiol. 2018;9:2419. doi: 10.3389/fmicb.2018.02419

30. Joachim A, Moyo SJ, Nkinda L, et al. Nasal Carriage of Methicillin-Resistant Staphylococcus aureus among Health Care Workers in Tertiary and Regional Hospitals in Dar es Salam, Tanzania. Int J Microbiol. 2018;2018:5058390. doi: 10.1155/2018/5058390

31. Warnke P, Frickmann H, Ottl P, Podbielski A. Nasal Screening for MRSA: Different Swabs - Different Results. PloS one. 2014;9(10):e111627. doi: 10.1371/ journal.pone. 0111627

32. Lavanya J, Jais M, Kumar V, Dutta R. Review Article Accessories of health care workers: a boon or a curse to patients in paediatric ICU and Nursery? Int J Curr Microbiol App Sci. 2013;2(10):441-447.

33. Daoudi A, Slitine N, Bennaoui F, Alaoui MM, Soraa Nabila, Maoulainine F. Study of Bacterial Contamination of Mobile Phones and Stethoscopes in Neonatal Intensive Care Unit. Int J of Ped. 2017;5(11):6139-6142. doi: 10.22038/ijp.2017.25504.2170

34. Lavanya J, Manoj J, Virendra K, Kumar GR. Bacterial Contamination of Healthcare Workers Accessories: A Potential Risk to Paediatric Intensive Care Unit and Nursery Patients. Int J of Microbiol Res. 2016;8(1):717- 
719.

35. Kotsanas D, Wijesooriya, Korman TM, Gillespie E, Wright L, Snook et al. Down the drain": carbapenemresistant bacteria in intensive care unit patients And handwashing sinks. Med J Aust. 2013;198(5):267-269. doi: $10.5694 / \mathrm{mja} 12.11757$

36. De Geyter D, Blommaert L, Verbraeken N, et al. The sink as a potential source of transmission of carbapenemase-producing Enterobacteriaceae in the intensive care unit. Antimicrob Resist Infect Control. 2017;6:24. doi: 10.1186/s13756-017-0182-3

37. Kramer A, Daeschlein G, Niesytto C, et al. Contamination of sinks and emission of nosocomial gramnegative pathogens in a NICU - outing of a reservoir as risk factor for nosocomial colonization and infection. Umweltmed
Forsch Prax. 2005;10(5):327.

38. Abubakar AS, Barma MM, Balla HJ, Tanimu YS, Waru $\mathrm{GB}$, Dibal J. Spectrum of bacterial isolates among intensive care units' patients in a tertiary hospital in north eastern Nigeria. Ind J Sci Res and Tech. 2014;2(6):42-47.

39. Montero JG, Lerma FA, Galleymore PR, et al. Combatting resistance in intensive care: the multimodal approach of the SpanishICU "Zero Resistance" program. Crit Care. 2015;19(1):114. doi: 10.1186/s13054-015-08005

40. Karam G, Chastre J, Wilcox MH, Vincent JL. Antibiotic strategies in the era of multidrug resistance. Crit Care. 2016;20(1):136. doi:10.1186/s13054-016-1320-7 